Revista Iberoamericana, Vol. LXVII, Núm. 196, Julio-Setiembre 2001, 497-506

\title{
APROXIMACIÓN SOCIAL A LA OBRA DE ROSA MARIA BRITTON
}

\author{
POR \\ HuMBeRTo LÓPEZ \\ University of Central Florida
}

Es un recuerdo lento, casi triste, definitivamente triste,

qué triste estoy, pero antes que rendirme a la pena apretaré los puños.

No se puede ser débil en un mundo de audaces.

Elsie Alvarado de Ricord, "Esta lluvia tenaz"

La labor literaria de Rosa María Britton (1936) ha venido en ascenso desde su primera novela, El ataúd de uso (1982) hasta sus publicaciones más recientes, la novela Todas íbamos a ser reinas (1997) y la recopilación de sus dramas en Rosa María Britton: Teatro (1999). ${ }^{1}$ A través de la pluma de Britton, la literatura panameña ha recibido un perfil dinámico y renovador. ${ }^{2}$ El propósito fundamental de este ensayo es incrementar el número de asedios a la obra de una escritora contemporánea que está contribuyendo notablemente al desarrollo de la literatura hispanoamericana. ${ }^{3}$ El radio de acción de este estudio estará principalmente enfocado hacia sus dos primeras novelas publicadas, El ataúd de uso y El Señor de las lluvias y el viento —ambas ganadoras del premio "Ricardo Miró”“4 (1982 y 1984, respectivamente) — y al trasfondo social que engarza y caracteriza ambas novelas.

\footnotetext{
${ }^{1}$ Este texto contiene tres dramas previamente publicados, Esa esquina del paraíso (1986), Banquete de despedida (1987), y Mi\$\$ Panamá (1989). Asimismo, incluye Los loros no lloran (1994), drama que nunca antes había ido a la prensa y que obtuviera el primer premio en la sección de teatro de los Juegos Florales en Quetzaltenango, Guatemala, en noviembre del mismo año.

${ }^{2}$ En diversos congresos literarios-dentro y fuera de los Estados Unidos- - he presentado trabajos sobre aspectos discursivos de la obra de Britton. He utilizado algunas de esas ponencias como base de este estudio haciendo énfasis en el siempre presente cuestionamiento de la identidad americana. ${ }^{3}$ En noviembre de 1997, Britton fue invitada por la ministra de Cultura de París para representar a Panamá en un Congreso de Literatura Centroamericana a celebrarse ese mes en la capital francesa. Esta distinción tan singular merece ser notada. El mismo mes, Britton acudió como invitada a la Feria Internacional del Libro, en Miami, para la presentación de su novela Todas íbamos a ser reinas.

${ }^{4}$ Este premio, otorgado anualmente en diversas categorías literarias, constituye el máximo galardón de la literatura panameña. Por estas dos novelas no han sido las únicas veces que Britton ha recibido el "Ricardo Miró". También le fue otorgado dicho premio por su libro de cuentos ¿Quién inventó el mambo?, (1985) y por teatro con Esa esquina del paraíso (1986) y Banquete de despedida, (1987). Posteriormente lo volvió a recibir por su novela No pertenezco a este siglo, (1991).
} 
La intertextualidad narrativa de Britton denota la presencia de voces marginadas que forman el diálogo y se incorporan al desarrollo de las novelas. Estos factores discursivos aportan otra visión al contexto. ${ }^{5}$ En ambas novelas, elementos enunciativos coinciden en una sorda denuncia de los aspectos sociales que la autora quiere exponer. Lidia Castillo, en su estudio sobre autores panameños, resalta que:

se considera que con la intertextualidad sale de su aislamiento el mensaje que se presenta como parte de un discurso desarrollado a través de textos o partes de textos, como diálogo cuyas frases son los textos o parte de los textos emitidos por los escritores. El fenómeno de la intertextualidad es frecuente sobre todo en los autores modernos. (91)

Los textos de Britton reflejan la modernidad aludida por Castillo, y más aún: la intertextualidad cumple con el propósito denunciatorio de la autora. ${ }^{6}$ Britton ofrece una aproximación sociológica con la cual se acerca a su realidad contemporánea. En su estudio sobre la literatura panameña, el crítico Ricardo Arturo Ríos Torres ha señalado que "Rosa María Britton aventura un diálogo sin formalismos entre el autor y el lector en el cual supera los imposibles, dejando a la vida misma gritar amplia y profundamente que todo puede suceder” (11-13). La relación que la autora busca, y obtiene, entre el texto y el lector es la clave para que el discurso de estas novelas exponga por sí mismo el objetivo de Britton.

Es revelador que, como parte de esta relación con el lector, la autora persiga una relectura donde exista más de una posibiblidad discursiva. Su escritura rompe la lectura convencional y proyecta otro ángulo de aproximación al texto. En ambas novelas, el acercamiento intertextual permite observar un mundo postergado que pretende ser parte de la sociedad y no logra su cometido. La dualidad entre el ser y el querer ser marca la dicotomía del personaje que, en ambas novelas, intenta su autoinclusión dentro del propio mundo que lo margina.

Los personajes más característicos para representar esta faceta de aproximación a las novelas de Britton son el pescador Manuel Muñoz, en El ataúd de uso, y la enfermera Alicia Castillo, en El Señor de las lluvias y el viento. Observar ambas novelas desde la percepción de estos personajes es enfrentarse al texto desde un ángulo diferente. Y si distinto es el acercamiento textual, diferente será también el resultado de ambas lecturas. Manuel y Alicia

\footnotetext{
${ }^{5}$ La intertextualidad narrativa de Britton fue analizada como parte mi ponencia para SECOLAS Southeastern Council of Latin American Studies— en San José, Costa Rica, febrero de 1997. Véase "Factores discursivos en la narrativa de Rosa María Britton: feminismo y negritud".

${ }^{6}$ Una vez expuesto el término de intertextualidad y ofrecido la cita de Lidia Castillo, referimos al lector a la definición de intertextualidad que ofrece Helena Beristáin y que se le atribuye al crítico Mikhail Bakhtin, donde expone que esta noción se desprende de la del principio dialógico que según el crítico ruso rige la orientación del enunciado literario (270). Soy consciente de la definición ofrecida por Julia Kristeva que apunta el término intertextualidad hacia la permutación de textos aunque no la utilice para el análisis de las novelas de Britton. Para más información sobre este término, consúltese el Diccionario de Retórica y Poética de Beristáin (269-72).

${ }^{7}$ Con el amanecer del día $1^{\circ}$ de enero de 2000, y de acuerdo al tratado Torrijos-Carter de 1977, las operaciones del canal fueron revertidas a manos panameñas. En estos momentos el canal opera bajo la completa supervisión de Panamá.
} 
ofrecen alternativas a una lectura lineal y sus horizontes se expanden y contraen de acuerdo al perímetro de acción en que la autora los sitúa.

Frente a estos personajes, desfila una sociedad de castas capaz de acorralar y/o aceptar a un individuo dependiendo de su estrato. Lo que expusiera Iván Schulman sobre la novela antiesclavista, "la idea que los pecados se heredan, o se repiten de modo implacable en una sociedad estática y corrupta” (328), atraviesa la diferencia cronológica e intersecta en diferentes puntos con las dos novelas que discutiremos; en ambas, la sociedad (y su visión del individuo) desempeña un papel preponderante. La propia escritora, refiriéndose a Panamá, manifestó que "este país es un crisol de razas y de costumbres y tratar de encajonar la identidad cultural en una sola dirección o en un solo grupo es un error muy grave” (Jaramillo Levi 41). La lectura de estas dos novelas de Britton — desde las perspectivas de Manuel y Alicia - constituye una acusación que no vacila en respaldarse en la historia para corroborar su denuncia social.

La historia panameña durante el siglo XX ha sido un compendio de emociones que ha delineado el perfil social del país. En los umbrales del siglo XX, en 1903, Panamá alcanza el reconocimiento político como nación independiente; en las postrimerías, la nación adquiere el control completo de las operaciones del canal que tanto ha influido en la identidad del panameño contemporáneo. ${ }^{7}$ La historia se reescribe en la narrativa de Britton; el crisol de razas mencionado por la autora se refleja en sus dos primeras novelas publicadas.

La historia es un factor fundamental para corroborar la denuncia del personaje marginado; Panamá, como nación, provee el telón de fondo necesario para el desarrollo de ambos textos. En su análisis sobre la novela hispanoamericana contemporánea, Seymour Menton ha expresado que "en el sentido más amplio, toda novela es histórica, puesto que en mayor o menor grado, capta el ambiente social de sus personajes” (31-32), para concurrir con la definición ofrecida por Enrique Anderson Imbert que aclara que las novelas históricas son "las que cuentan una acción ocurrida en una época anterior a la del novelista” (33). ${ }^{8}$

Britton recurre a la historia como zócalo de apoyo para sustanciar una narrativa no siempre estrictamente histórica y expone la época y los espacios logrando transportar al lector al seno del enunciado. En sus cuatro novelas publicadas la historia ha desempeñado un papel significativo. ${ }^{9}$ La estructura de la trama se enmarca dentro del contexto histórico

\footnotetext{
${ }^{8}$ Véase el texto de Georg LukácsThe Historial Novel donde habla sobre la forma clásica de la novela histórica (19-30) para un mejor entendimiento de la base de la teoría expuesta por los dos críticos anteriormente citados.

${ }^{9}$ Las otras dos novelas de Britton, no analizadas como parte de este estudio, contienen también un trasfondo histórico significativo. No pertenezco a este siglo (1989), se desarrolla en una Colombia decimonónica donde se enfrenta la lucha por una región del país en devenir independiente. Recuérdese que Panamá obtuvo su independencia de Colombia y se erigió como nación en 1903. Britton indicó en una entrevista que la razón para escribir No pernezco a este siglo fue para "demostrar a través de una novela de que mucho antes de que los franceses intentaran convertirnos en un canal, ya los panameños buscaban a través de veintidós movimientos separatistas, la independencia de Colombia” (López Cruz "Rosa María Britton: nuevo perfil” 124-25). Y refiriéndose al personaje principal señaló que "me costó mucha investigación esta novela y el personaje central acabó por posesionarse de mí [... ] creo que José Hilario cumplió su cometido y si nunca existió merece un puesto en la historia” (125). La otra novela, Todas íbamos a ser reinas (1997), tiene como telón de fondo
} 
para otorgar a la narrativa una exposición lógica donde el lector deberá incorporarse al llamado del texto para así lograr una mejor ubicación del período seleccionado.

Ahora bien, al enfocar la estructura narrativa en el acercamiento que propongo a las novelas de Britton, es necesario subrayar las características esenciales señaladas por Yolanda Salas sobre una relación estructural y una visión conceptualista del modelo social, en una exposición sobre la ideología del lenguaje. ${ }^{10}$ La narrativa de Britton responde a un análisis social en que la consciencia individual es absorbida por una consciencia colectiva. La estructura social reflejada en ambos textos, El ataúd de uso y El Señor de las lluvias y el viento, no permite que el individuo se aventure en esferas opuestas a lo previamente dictaminado por la sociedad. Al transgredir las normas sociales y traspasar el perímetro de acción preconcebido, el individuo se arriesga al rechazo y a la condena. Se ha señalado que "el haber violado uno de los preceptos más arraigados en la infraestructura social expuesta, provoca un desajuste en el desenvolvimiento y evolución del personaje que ha de culminar con una ruptura o con el aislamiento social del individuo” (López Cruz, 55). La ruptura ocurre para denunciar la estratificación social y, al mismo tiempo, lograr la autoubicación del personaje dentro del círculo que le corresponde.

En El ataúd de uso, el personaje central alrededor de quien gira la narración, es Manuel Muñoz. ${ }^{11}$ Manuel es la representación del conglomerado negro que se enfrenta a la sociedad; un individuo que intenta su propio desarrollo evolucionando desde su microcosmos, su Chumico natal, hasta el macrocosmos de la capital, la ciudad de Panamá. Britton, en un ambicioso proyecto, denuncia la vejación racial y la hace extensiva a toda la capital. El texto indica que en la capital "pocos gustan de los negros [...] la gente sigue igualita con sus prejuicios aunque tratan de disimularlo un poquito más ahora, pero con cualquier excusa le sacan a uno lo de negro y pobre” (65). La autora presenta una capital polarizada donde la diferencia racial es una constante notable. Es un hecho significativo que la trama se desarrolle en Panamá, centro de gran afluencia internacional desde la época de la Colonia. Castillero Calvo indica que "la sociedad colonial, como la española, estaba rígidamente jerarquizada. Y la legislación urbana, como era de esperarse, habría de reflejar con claridad

\footnotetext{
un importante período de la historia cubana. El gobierno de Fulgencio Batista y la revolución de Fidel Castro, que culminaría en la victoria del último el primero de enero de 1959, marcan a las protagonistas que deben organizar sus vidas a partir de este evento histórico. En la misma entrevista, Britton expuso que "las reinas es un paseo a través de mis memorias de Cuba, esa Cuba que no deja de dolerme y sin saber qué hacer al respecto” (125). La historia complementa la narrativa de ambas novelas donde el lector debe familiarizarse con una relación de los acontecimientos acaecidos para lograr un mejor entendimiento del texto.

${ }^{10}$ Véase el estudio de Yolanda Salas en el que entre otros señalamientos propone que "la consciencia colectiva, que no es única sino plural, se realiza mediante la visión del mundo o consciencia posible de una clase. Esta visión que debe ser conceptualmente construida mediante el análisis de la clase considerada y su intersección en la estructura global, expresa además una escala de valores que es inherente a su organización social” (8). Los textos que se presentan de Rosa María Britton pueden encajar dentro de lo expuesto por Salas donde intersectan el individuo y la sociedad.

11 "El negro" como elemento discursivo en El ataúd de uso fue presentado en mi ponencia para CILCA '95 - Congreso Internacional de Literatura Centroamericana- en Ciudad de Guatemala, Guatemala, febrero de 1995.
} 
esos valores jerarquizantes” (27). Esta jerarquía trasciende al texto, visualizándose la estructura social y la dificultad, y hasta cierto punto incapacidad, del individuo de autoincluirse en la sociedad en que se desenvuelve. ${ }^{12}$

Un aspecto notable lo establece el matrimonio interracial entre Manuel y Carmen, la maestra blanca del pueblo. El concepto del hibridismo racial y cultural latinoamericano constituye un eslabón unificante, aspecto que contribuye a la unificación intertextual de ambas novelas. ${ }^{13}$ El mestizaje que propone Britton en El ataúd de uso ha existido siempre al encontrarse dos razas o culturas disímiles. Sobre este punto, Ríos Torres ha señalado la realidad de “absurdos prejuicios raciales en un país el cual es síntesis de un intenso mestizaje físico-cultural” (10).

En casos como éste, el lector se convierte en parte integral del texto, ya que éste es el arma de denuncia de la autora. La relación de Manuel y Carmen, negro y blanca, suscita un rechazo colectivo por parte del círculo social de Carmen. Ésta, segura de sí misma, abandona a los suyos para establecerse en el pueblo de su marido. Carmen es firme y determinada en su postura, pero es rechazada por su madre y hermanas: la identidad de Carmen se cuestiona tras su unión con Manuel. Este cuestionamiento aflora debido a un rechazo social que no sólo va a afectar a la pareja sino a su futura descendencia. El relato expone la contradicción existente dentro de una pluralidad social mestiza que a través de la madre y las hermanas de Carmen niega un aspecto inevitable en la formación de la híbrida América. Diógenes Fajardo Valenzuela ha expresado que "el planteamiento de la problemática de la identidad en términos de seducción lleva implícita una polémica que todavía no se resuelve completamente. La de relacionar identidad con localismo y universalidad con cosmopolitismo", para agregar que "como la búsqueda de la identidad no se realiza en forma abstracta, es preciso recordar que este doble proceso de unidad dentro de la diversidad y de universalización a partir de la singularidad se da en un contexto histórico que condiciona y es condicionado por la identidad” (69-70).

El cosmopolitismo de la ciudad de Panamá es el espacio idóneo para mostrar la segregación racial y es allí donde Manuel atraviesa momentos de inseguridad que de otro modo no experimentaría en el microcosmos de su espacio local, o sea en su Chumico natal. Manuel podrá resolver sus inquietudes sociales en su pueblo; sin embargo, quedará marcado para siempre con las cicatrices infligidas por una sociedad capitalina que ya, de antemano, lo había clasificado como miembro de una casta inferior.

\footnotetext{
${ }^{12}$ Véase el estudio de Castillero Calvo para una completa descripción de la historiografía urbana colonial de la ciudad de Panamá. Este análisis muestra claramente la estructura jerárquica de la capital, así como la marginación experimentada en los arrabales.

${ }^{13}$ Sobre el concepto de hibridismo en América Latina, véase el texto de Néstor García Canclini, Culturas híbridas: estrategias para entrar y salir de la modernidad. Entre otros puntos, el autor propone que "hoy concebimos a América Latina como una articulación más compleja de tradiciones y modernidades (diversas, desiguales), un continente heterogéneo formado por países donde, en cada uno, coexisten múltiples lógicas de desarrollo” (23). Este concepto respalda la re-lectura que propongo de los textos de Britton desde el punto de vista de la voz marginada.
} 
En El Señor de las lluvias y el viento, ${ }^{14}$ la presencia negra es más notable. Las dos historias que corren paralelas ante el lector están protagonizadas por elementos marginados. ${ }^{15}$ Tanto la enfermera Alicia como el curandero Andrés representan una presencia racial precondenada dentro de una sociedad donde el mestizaje no es un fenómeno novedoso. ${ }^{16}$ Considerando el trasfondo histórico de Panamá, el mestizaje ha llegado a un nivel más desarrollado que en otros puntos del Caribe insular donde la presencia india desapareció casi completamente. En Panamá, el indio, el negro y el blanco corroboran el hibridismo que caracteriza a América. ${ }^{17}$ Sin embargo, es necesario señalar lo expuesto sobre la negritud en función directa con el discurso textual, ya que "no rige el desarrollo de la narrativa de Britton; sin embargo, su esencia está presente al manifestarse dentro de una sorda denuncia de la discriminación racial que sufren los protagonistas negros” (López Cruz, "La negritud” 54). Implícitamente, la autora incluye al negro en el tejido de la trama; aquí el personaje interactúa con el texto y se convierte en la voz que el lector sigue, con la que se identifica, y es también la voz que afecta el desarrollo de los otros personajes. No obstante, la negritud continúa siendo motivo de división social y, por consiguiente, la continuación de un patrón narrativo que previamente se observara en El ataúd de uso.

En el caso de Alicia, en El Señor de las lluvias y el viento, Britton ofrece un personaje mucho más elaborado. La marginación del personaje ocurre desde el nacimiento de ésta en el seno de una familia blanca — a consecuencia de supuestos amores ilícitos de la madre con un hombre de la raza negra que fuerza el mestizaje — provocando la locura de su madre poco después de su nacimiento, ${ }^{18}$ la ira de la abuela y el desprecio de la sociedad. ${ }^{19}$

Para lograr el desarrollo estructural narrativo que enfoca la marginación de su personaje, la autora involucra a otros personajes y de ese modo ofrece una propuesta que expone su cometido. Uno de los hechos más evidentes es el encuentro fortuito de la muchacha con una pareja de hermanos peruanos durante la travesía en barco de Panamá a los Estados Unidos. Aquí se ve cómo la autora traslada la acción fuera del terreno panameño e incluye a extranjeros que de esta manera contribuyen a la universalización del conflicto.

\footnotetext{
${ }^{14}$ Se cita por la edición de Litografía e Imprenta LIL, S.A., Costa Rica, 1989.

${ }^{15}$ La marginación social y sus consecuencias dentro del discurso de El Señor de la lluvias y el viento fue parte de mi ponencia para CILCA '96 — Congreso Internacional de Literatura Centroamericanaen San Salvador, El Salvador, febrero de 1996.

${ }^{16}$ Para este estudio, la sección del texto que corresponde a Andrés y su problemática individual no será analizada. La excepción, claro está, será la parte de esta historia que intercepte con la de Alicia propia.

${ }^{17}$ Sobre este punto, véase lo señalado por Lorna $\mathrm{V}$. Williams que indica que el indio no fue totalmente exterminado en Panamá y sigue constituyendo una presencia étnica significativa (11). Consúltese el artículo de Williams para una aproximación más detallada de un aspecto fundamental en la composición híbrida del Panamá contemporáneo.

${ }^{18}$ Un hecho similar se aprecia en la novela decimonónica antiesclavista Cecilia Valdés, de Cirilo Villaverde, donde la madre de Cecilia pierde la razón al arrebatársele la recién nacida de sus brazos. Sin embargo, en el epílogo de la novela de Villaverde madre e hija logran reunirse, hecho que no ocurre en El Señor de las lluvias y el viento.

${ }^{19}$ El tema de la negritud que aflora en las dos primeras novelas de Britton fue analizado en mi ponencia presentada durante el $47^{\circ}$ Congreso Literario de MIFLC—Mountain Interstate Foreign Language Conference—en Greenville, North Carolina, octubre de 1997.
} 
Con respecto a El ataúd de uso, los parámetros se modifican ligeramente aunque el resultado sea el mismo en El Señor de las lluvias y el viento. La dicotomía presentada por Fajardo Valenzuela va a hallar una variante. La movilidad de Alicia como personaje va a lograr que el extranjero represente lo cosmopolita, mientras que la nación (Panamá) se perciba como el espacio local.

Desde el primer encuentro se advierte una atracción por parte de Carlos hacia Alicia y la consecuente turbación de ésta. En todo momento la diferencia racial se presenta como obstáculo, no sólo como entorpecimiento a las incipientes relaciones entre los dos jóvenes, sino como impedimento a la integración de Alicia a la sociedad de la que aspira a ser parte. Hasta este momento de su vida se puede afirmar que ella nunca se ha visto como parte del ambiente que la rodea, más bien lo contrario. Los ambientes recreados por Britton han situado a Alicia en el desnivel necesario para que desde este punto de la narrativa en adelante el lector comprenda el poco valor social que se le otorga a la muchacha. Al ser hija ilégitima — y de padre negro - el desprecio de los que la rodean no se hizo nunca esperar. Sus inquietudes religiosas son subestimadas por un Cardenal romano quien escribió al párroco del barrio, "no es fácil encontrar refugio a la vocación de una señorita de la raza que usted describe" (20-21). La argucia de enviarla a Boston a un convento que acepta novicias negras se convirtió en bálsamo esperanzador para la abuela que vio en esta partida la forma de deshacerse decorosamente de Alicia. Pueden repasarse las palabras de la anciana al comunicarle el párroco la cantidad que exigía como dote el convento bostoniano para así aceptar a una novicia negra:

¿Mil dólares? ¿Ha dicho usted dos mil pesos para que Alicia pueda meterse a monja? [...]. ¿De dónde?-chilló la vieja, asustada al darse cuenta de que a lo mejor jamás podría librarse de la nieta que con su presencia le recordaba a cada minuto a la hija que murió encerrada en el manicomio, víctima de un pecado mortal con un desconocido. (21)

La movilidad de los espacios, característica ya antes vista en El ataúd de uso, ${ }^{20}$ traslada la narrativa del Panamá natal de Alicia a un Miami de la década de los treinta donde la segregación racial de la época impide un almuerzo conjunto en cualquier restaurante local. ${ }^{21}$ La hermana de Carlos es la que rememora el incidente:

Carlos se empeñó en acompañar a la panameña que hablaba muy poco inglés [...] y ya sabes cómo es el asunto con los negros en el sur. En ninguna parte nos querían servir, porque andábamos con ella y Carlos le sacaba la comida a la calle y se sentaban los dos a comer en cualquier parte. ¡Las vergüenzas que me hizo pasar! (41)

El muchacho la acepta sin condiciones, pero la alta alcurnia en la que él se desenvuelve no va a admitir la unión de dos razas. La síntesis de la argumentación de Britton puede considerarse como la deshumanización del conflicto y su visión pluralista en el continente latinoamericano; la historia tiene que reescribirse a partir del enunciado híbrido que

\footnotetext{
${ }^{20}$ Esta característica sería una constante repetitiva en sus dos novelas posteriores.

${ }^{21}$ La acción se desarrolla durante 1932. Las leyes que amparaban la segregación racial no están vigentes en la actualidad.
} 
representa a América. Richard Jackson ha insinuado lo que pudiera considerarse un fuerte puntal en la narrativa de Britton. Jackson expresa que "concerned authors, particularly novelists, tried to show what it was like to be human in that part of the world, and they exposed human suffering and other dehumanizing qualities of life that threaten man's dignity” (1-2).

A pesar de la lucha de Carlos, en gran parte consigo mismo, triunfa lo implantado por la sociedad; y el romance, que a su debido momento llegará a consumarse, termina. No obstante, el episodio del romance abarca desde la fogosidad del muchacho en probarle su incipiente amor, hasta el abandono de éste cuando ve que el compromiso matrimonial está condenado a disolverse. Sin embargo, Alicia es la que que establece las coordenadas de la narrativa. Carlos expone: "Nos casaremos en la Catedral de Lima, en misa de doce, promete aliviado. Con toda mi parentela de gala ¡Cómo te va a querer mi tío Sebastián!. El siempre gustó de las morenas de la costa. Y usted, es lo más lindo del mundo” (142).

La negativa por parte de Alicia al intento de boda es el recurso que utiliza la autora para situar a la pareja en el sitio que corresponde en la escala social y demostrar la consciencia del personaje al enfrentar la encrucijada. En todo momento Alicia reconoce su situación; no se puede alegar que Britton ha creado un personaje ajeno a la realidad del momento. Estos altibajos emocionales son los que van delineando la búsqueda de identidad por parte de Alicia que nunca asume el papel de mujer-víctima, más bien el lector intuye que es ella quien maneja los hilos de la trama y hace que día a día presienta el devenir de hechos que acepta con objetividad y lucidez. La presencia femenina en los textos de Britton, rompe con lo que una sociedad paternalista espera de la mujer; la autora subvierte el texto al situar a sus protagonistas femeninas en un ángulo inesperado y con consciencia de sus propias acciones. Sobre la situación de la mujer en Panamá, Mariblanca Staff Wilson ${ }^{22}$ — una voz destacada en el ámbito social panameño— ha apuntado que:

es innegable que a través de los siglos, la concepción patriarcal que ha prevalecido en el mundo, ha sido plasmada en los distintos instrumentos nacionales e internacionales, al considerar al hombre (varón) como paradigma de la humanidad; situación que se ha reflejado en los derechos humanos, en su lenguaje, en sus ideas, valores, costumbres y hábitos, pues los mismos sólo tienen como referencia a una parte de la humanidad: la masculina, a través de cuyos sentimientos y pensamientos se nos ha ubicado en la sociedad, como seres inferiores, sumisas y dependientes, sin derecho a nuestra propia identidad genérica. (12)

Alicia destruye el patrón preconcebido, ya que Britton maneja a su heroína de forma que no sólo anticipe sino dicte el comportamiento de Carlos. Éste a su vez es la herramienta para que el discurso de la autora se complemente y, al mismo tiempo, para que Alicia, sola, continúe la búsqueda de su identidad. El hibridismo latinoamericano, lentamente, ocupa el sitio que le corresponde. El fracaso matrimonial que experimentara Carmen en El ataúd de uso no se repite en El Señor de las lluvias y el viento ya que la unión legal de Carlos y Alicia no se lleva a cabo. El muchacho, una temporada más tarde de aquélla en que prometió

${ }^{22}$ Mariblanca Staff Wilson es abogada y al momento de escribirse este artículo funge como directora del Registro Público en Panamá (130). 
contraer matrimonio en la catedral de Lima, prepara su retirada ya que no quiere continuar siendo parte de la marginación social, que a través de Alicia, la sociedad le hace extensiva a él. Carlos se justifica ante Alicia:

no quiero que desperdicies tus conocimientos en ese Hospital. Me ha costado bastante ahorrar lo suficiente para que regreses. En tu país llegarás a ser lo que te propongas y cuando yo termine te iré a buscar [...] (“Alicia, Alicia, lo nuestro es imposible, mi familia está enterada, [...] las cartas que han escrito, mi amor [...] sobre todo mi madre [...] hasta el tío Sebastián se preocupó del aspecto legal tuyo y mío [...]”). (152)

Este rechazo por parte de la familia de Carlos es el mismo eco social observado en $E$ l ataúd de uso. En ambas novelas, la sociedad condena una unión interracial; el personaje blanco en la relación es quien sufre la presión directa, mientras que el negro recibe una opresión indirecta que corrobora el poco valor que se le otorga en la escala social. La realidad de la híbrida América Latina se intenta ocultar ante lo impuesto por la sociedad; ésta es la entidad que cuestiona la veracidad de un enunciado socio-cultural. El romance AliciaCarlos es el eje sobre el cual Britton sitúa a su heroína para que a su alrededor transcurra el desarrollo de la muchacha como personaje. El resultado: la aceptación de Alicia de su condición y posición social, y el crecimiento de su personaje que concientiza su condición de género y raza.

Ambos textos, El ataúd de uso y El Señor de las lluvias y el viento, ofrecen al lector nuevas posibilidades discursivas. La problemática que presentan estos textos puede ya haber sido presentada con anterioridad; no obstante, sigue siendo vigente la denuncia sobre problemas que confronta la sociedad latinoamericana. Rosa María Britton enfrenta el tema de la marginación social con agresividad y deja que sus personajes busquen y encuentren el sitio que les corresponde dentro del mosaico cultural en que se desenvuelven; sin embargo, el lector debe escuchar la voz marginada que se repite en ambos textos para así establecer la comunión requerida con el enunciado denunciatorio que expone la autora.

Bibliografía

Beristáin, Helena. Diccionario de Retórica y Poética. México, DF: Editorial Porrúa, 1997. Britton, Rosa María. Rosa María Britton: Teatro. Panamá: Editorial Mariano Arosemena, 1999.

Todas íbamos a ser reinas. Santafe de Bogotá: Plaza \& Janes Editores, 1997. No pertenezco a este siglo. Panamá: Editorial Mariano Arosemena, 1991.

El Señor de las lluvias y el viento. Costa Rica: Litografía e Imprenta LIL, S.A., 1989. El Señor de las lluvias y el viento. Panamá: Editora Sibauste, S.A., 1989.

El ataúd de uso. Bogotá: Editorial Oveja Negra, 1986.

¿Quién inventó el mambo? Panamá: Editorial Mariano Arosemena, 1986.

Castillero Calvo, Alfredo. "La experiencia urbano colonial: Contexto ideológico-emblemático

y funcionalidad. Ensayo de interpretación sobre el caso panameño”. Lotería 409 (1996): 6-31.

Castillo, Lidia E. “Intertextualidad en obras de autores panameños”. Lotería 408 (1996): 91101. 
Fajardo Valenzuela, Diógenes. “Identidad y aporte de la literatura del Caribe”. América negra. Pontificia Universidad Javeriana 5 (1993): 65-77.

García Canclini, Néstor. Culturas híbridas: estrategias para entrar y salir de la modernidad. México: Grijalbo, 1989.

Jackson, Richard L. Black Literature and Humanism in Latin American. Athens, GA: University of Georgia Press, 1988.

Jaramillo Levi, Enrique. Ser escritor en Panamá: entrevistas a 29 escritores panameños al finalizar el siglo XX. Panamá: Fundación Pro-Biblioteca Nacional, 1999.

López Cruz, Humberto. "Factores discursivos en la narrativa de Rosa María Britton: feminismo y negritud”. SECOLAS Annals 29 (1998): 55-60.

"La negritud como la historia no oficial en las dos primeras novelas de Rosa María Britton”. Romance Notes 39/1 (1998): 53-60.

"Rosa María Britton: nuevo perfil de la literatura panameña”. Confluencia 15/1 (1999): 121-26.

Lukács, Georg. The Historical Novel. Hannah y Stanley Mitchell, trads. Lincoln: University of Nebraska Press, 1983.

Menton, Seymour. La nueva novela histórica de la América Latina, 1979-1992. México: Fondo de Cultura Económica, 1993.

Ríos Torres, Ricardo Arturo. Las raíces compartidas: reseñas críticas en torno a publicaciones panameñas. Panamá: Editorial Universitaria, 1993.

Salas de Lecuna, Yolanda. Ideología y lenguaje en la narrativa de la modernidad. Caracas: Monte Avila Editores, 1992.

Schulman, Iván A. “Tanco y la literatura antiesclavista”. Homenaje a Lydia Cabrera. Reinaldo Sánchez, José Antonio Madrigal, Ricardo Viera, José Sánchez-Boudy, eds. Miami: Ediciones Universal, 1978. 317-32.

Staff Wilson, Mariblanca. “Mujer y derechos humanos”. Lotería 417 (1998): 6-33.

Williams, Lorna V. "Carlos Guillermo Wilson and the Dialects of Ethnicity in Panamá". Afro-Hispanic Review 4/2-3 (1985): 11-16. 